\title{
EDUCAÇÃO FÍSICA E SAÚDE NA EDUCAÇÃO INFANTIL: FUNDAMENTOS TEÓRICO- FILOSÓFICOS EM DEFESA DO CONHECIMENTO EM SUAS FORMAS MAIS DESENVOLVIDAS NA ESCOLA*
}

\author{
Celi Nelza Zülke Taffarel \\ Cássia Hack ${ }^{2}$ \\ Márcia Morschbacher ${ }^{3}$
}

\section{Introdução}

Neste texto discutimos conceitos de saúde redimensionando-os no trato do conhecimento no âmbito da disciplina de Educação Física relacionado à responsabilidade e à função social da escola, ampliando as referências sobre saúde para uma ação com base científica na vida concreta e não na pseudoconcreticidade (KOSIK, 1976) ${ }^{4}$. Desta feita, evidenciamos a relevância da escola, do currículo e do conhecimento científico da Cultura Corporal baseadas em argumentos no campo da teoria do conhecimento e da teoria pedagógica.

Apresentamos uma síntese acerca dos conceitos sobre "saúde" e

\footnotetext{
* 10.29388/978-65-86678-46-8-0-f.31-48

${ }^{1}$ Universidade Federal da Bahia (UFBA). Produtividade em Pesquisa do CNPq. E-mail: celi.taffarel@gmail.com

${ }^{2}$ Universidade Federal do Amapá (UNIFAP). E-mail: cassia.hack@gmail.com

${ }^{3}$ Universidade Federal de Santa Maria (UFSM). E-mail: mm.edufisica@yahoo.com.br

${ }^{4}$ Conforme Kosik (1976, p. 11, grifos do autor): “O complexo dos fenômenos que povoam o ambiente cotidiano e a atmosfera comum da vida humana, que, com a sua regularidade, imediatismo e evidência, penetram na consciência dos indivíduos agentes, assumindo um aspecto independente e natural, constitui o mundo da psendoconcreticidade. A êle pertencem: - $\mathrm{O}$ mundo dos fenômenos externos, que se desenvolvem à superfície dos processos realmente essenciais; - O mundo do tráfico e da manipulação, isto é, da práxis fetichizada dos homens (a qual não coincide com a práxis crítica revolucionaria da humanidade); - o mundo das representações comuns, que são projeções dos fenômenos externos na consciência dos homens, produto da práxis fetichizada, formas ideológicas de seu movimento; - o mundo dos objetos fixados, que dão a impressão de ser condições naturais e não são imediatamente reconhecíveis como resultados da atividade social dos homens.".
} 
algumas perspectivas de compreensão do campo da Educação Física. Desta maneira, não propomos (re)biologicizar a Educação Física e nem a formação humana. Trata-se de incorporar por superação elementos necessários para a compreensão, constatando e explicando nexos e relações para uma abordagem científica de totalidade. Isto significa que é necessário aprofundar estudos para o trato do conhecimento a partir de um Sistema de Complexo enquanto lógica dialética. Deste apontamento, nos baseamos em fundamentos sobre as dimensões do conhecimento operacional e teórico, que só se desenvolvem com a incidência em funções psicológicas que ampliam a capacidade humana de constatar, compreender, ampliar e aprofundar o conhecimento teórico.

A Saúde é um conhecimento científico relacionado historicamente com a Educação Física. As determinações históricas da vida humana e o conhecimento daí gerado sobre Saúde precisam ser compreendidas e explicadas cientificamente se almejamos a formação omnilateral, haja vista a fragmentação, a fragilidade e a desestruturação histórica do pensamento científico, quando o fenômeno é conhecido em partes, isolado e deslocado da totalidade e de forma pueril, impingindo conotações e assertivas negativas ou superdimensionadas ao fenômeno, este que se constitui denso possibilitando uma abordagem de compreensão crítica da realidade que sinaliza à superação da sociedade de classes enquanto teleologia, enquanto projeto histórico. Portanto, para uma formação humana na perspectiva da emancipação da classe trabalhadora, a formação omnilateral é imprescindível.

Omnilateral é um termo que vem do latim e cuja tradução literal significa "todos os lados ou dimensões". Educação omnilateral significa, assim, a concepção de educação ou de formação humana que busca levar em conta todas as dimensões que constituem a especificidade do ser humano e as condições objetivas reais para seu pleno desenvolvimento histórico (FRIGOTO, 2012, p. 267, grifo do autor).

Portanto, a formação humana não se dá abstratamente, mas sim nas relações sociais concretas produzidas historicamente. Segundo Ramos (2009):

[...] a formação omnilateral, cujo horizonte é a emancipação humana, implica a apreensão das determinações históricas da realidade em que se vive, ou seja, das relações que constroem e configuram o processo histórico de produção da existência, mediado pela 
própria ação humana, ao qual chamamos de trabalho. (RAMOS, 2009, p. 167).

Partindo desses fundamentos sobre a formação humana, admitimos que a possibilidade de acesso dos sujeitos aos bens desenvolvidos pela humanidade, sobre a realidade concreta, a luta de classes, o conhecimento nas suas formas mais desenvolvidas, é vital, mas, apresenta uma contradição na Escola (SAVIANI; DUARTE, 2012), a sua negação. O conhecimento, por exemplo, sobre Saúde, é parte constitutiva dos meios de produção, que, nesta sociedade, são propriedade privada do capital e são, portanto, negados, manipulados ideologicamente. As ideias da eugenia e higienismo (SOARES, 2017) que sustentaram e, ainda sustentam, o racismo estrutural (ALMEIDA, 2019), penetraram e ainda penetram o processo de escolarização, via trabalho educativo na escola, através das aulas de Educação Física.

\section{O conhecimento sobre saúde e sua relação com a Educação Física}

As várias concepções de saúde são formuladas a partir do embate de projetos societários e concepções de mundo que defendem interesses antagônicos de classe e, assim, se desenvolvem e são selecionadas, por políticas curriculares nacionais, sob a égide do pós-modernismo e suas expressões, como o relativismo cultural e o multiculturalismo, colaborando com o ultra-neoliberalismo na legitimação do capitalismo (MALANCHEN, 2016).

Pode-se apropriar de parte do desenvolvimento destas concepções a partir da história da reforma sanitarista no Brasil e América Latina ${ }^{5}$.

No modo de produção capitalista, a saúde é tratada como mercadoria, portanto, a saúde é para poucos, os poucos que podem pagar por ela. Nesta perspectiva, há uma ênfase no pensamento econômico que trata a relação direta entre pobreza e doença, desconsiderando outros determinantes, e uma ênfase na justiça social, que designa a saúde e a educação como características de desenvolvimento - tese assumida pelos es-

${ }^{5}$ Ver dissertação de Pinto (2012) e as produções de Paim, como por exemplo: PAIM, J. S. Reforma sanitária brasileira: contribuição para compreensão e crítica. Salvador: EDUFBA; Rio de Janeiro: Editora FIOCRUZ, 2008.; e PAIM, J. S. Bases conceituais da reforma sanitária brasileira. In.: FLEURY, S. (Org). Saúde e Democracia: a luta do CEBES. São Paulo: Lemos Editorial, 1997. 
tudos que se multiplicam acerca dos determinantes sociais acerca da saúde (ALMEIDA FILHO, 2009) em uma perspectiva que trata da Saúde a partir da Saúde Pública, Saúde Coletiva ${ }^{6}$ e Saúde em Ciências Sociais. Áreas que aos poucos a Educação Física se permite aproximar para reelaborar a sua concepção de Saúde e consequentemente suas formas de formação e atuação com este fenômeno.

A década de 1980 é o marco temporal do momento em que as Ciências Sociais e Humanas despontam com relevância no campo de conhecimento da Educação Física Brasileira. Estabelece-se diálogo com as disciplinas que fundam as Ciências Sociais e Humanas e a Educação Física que, até então, ocupava-se restritamente na área das Ciências Biológicas e da Saúde. É um período tratado por autores da vertente cultural da Educação Física como a "desbiologização" da Educação Física (STIGGER, 2015).

Há, no campo de conhecimento da Educação Física numerosos estudos $^{7}$ sobre Saúde no amplo leque de compreensão do fenômeno, contudo, majoritariamente com acento biologizante bastante efusivo, pois não tratam o fenômeno Saúde em sua totalidade com as determinações sociais, econômicas, políticas, culturais, e outras envolvidas bem como as suas relações, e nem na perspectiva de um projeto histórico de sociedade humanizante.

Segundo Devide (2002), na Educação Física há ao menos duas perspectivas de compreensão da Saúde: a promoção da saúde (Health Promotion) e a Aptidão Física Relacionada à Saúde (Health Related Fitness). Ba-

\footnotetext{
${ }^{6}$ Compreensão histórica de Saúde Pública e Saúde Coletiva como diferentes noções vinculadas a ideologias, conceitos articulados às teorias, valores, compromissos, projetos societários e lutas sociais distintas. Saúde Pública formulação institucionalizada, verticalizante, individualizada, assistencial, curativa em tempos ditatoriais. Saúde Coletiva nasce da crítica à saúde pública, vem no bojo da transformação do pensamento na reforma sanitária iniciadas nas décadas de 1970/1980, como projeto orgânico de reforma social, de conotação abrangente e possibilidade contra hegemônica de caráter de ação coletiva, uma elaboração acadêmica de um espaço social mais amplo e complexo (PAIM, J. S. Saúde Coletiva ou restauração da Saúde Pública? Palestra na Escola de Saúde Pública. 2014). Ver mais nas produções do Professor Jairnilson Silva Paim, da Universidade Federal da Bahia.

${ }^{7}$ Nahas (1989); Faria Júnior (1991a, 1991 b); Nahas, Corbin (1992); Guedes e Guedes (1993, 1994); Ferreira, (1993, 2001); Soares (1994); Oliveira, Devide (1996a, 1996b, 2000); Carvalho (1993, 1997, 2001a; 2001b; 2006); Carvalho, Rubio (2001); Bagrichevsky, Palma, Estevão (2003; 2007); Bagrichevsky, Palma, Estevão, Da Ros (2006); Fraga, Wachs (2007); Pinho (2011); Fraga, Carvalho, Gomes (2012); Pinto (2012); Carvalho, Gomes, Fraga (2015); Stigger (2015); Wachs, Almeida, Brandão (2016); Prado, Carvalho (2016).
} 
grichevsky e Palma (2004, p. 2) indicam que há na Educação Física a partir de "sua gênese orientada a partir de um ideário militar de disciplinamento e controle biopolítico de corpos, que buscava extrair-lhes, ao máximo, uma funcionalidade servil" um legado das 'práticas higienistas' do início do século XX e à 'promoção da saúde' do quarto final do mes mo século que foi engendrando o "que se convencionou chamar de 'Movimento da Saúde’ (SOARES, 1994; FRAGA, 2003; GÓIS JÚNIOR e LOVISOLO, 2003)". Em uma abordagem que privilegia os aspectos fisiológicos e as quantificações biológicas hegemônicas em detrimento de outros enfoques, numa relação de 'causa e efeito', ou seja, a saúde como consequência da prática regular de atividade física. Ao tempo que apontam indícios de estudos consistentes na Educação Física com "perspectivas de enriquecimento do debate crítico acerca do fenômeno (MAIA, 1996; DELLA FONTE e LOUREIRO, 1997; CARVALHO, 2001; PALMA, 2001a; PALMA, 2001b; MIRA, 2000)" (BAGRICHEVSKY; PALMA, 2004, p. 3).

Há também certo consenso em parte do campo da Educação Física que a relaciona especificamente com os estudos organizados a partir do campo da Epidemiologia. Se considerarmos etimologicamente o termo, "epidemiologia" significa o estudo que afeta a população (epi= sobre; demio= povo; logos= estudo). Há diferentes conceituações acerca do seu desenvolvimento bem como de sua base científica, ora na Saúde Pública, ora na Saúde Coletiva. Congrega métodos e técnicas de três áreas principais do conhecimento: Matemática (Estatística), Ciências da Saúde/Saúde Pública/Saúde Coletiva ${ }^{8}$, Ciências Sociais (Antropologia, Economia Política, Sociologia). Quanto a conceituação ${ }^{9}$, pode ser definida como a ciência que estuda o processo saúde-doença em coletividades humanas, analisando a distribuição e os fatores determinantes das enfermidades, danos à saúde e eventos associados à saúde coletiva, propondo medidas específicas de prevenção, controle ou erradicação de doenças, e fornecendo indicadores que sirvam de suporte ao planejamento, administração e avaliação das ações de saúde. Constitui-se na principal ciência de informação de saúde.

Há também certo consenso em outra parte do campo da Educação Física que se utiliza de instrumentais do que se convencionou deno-

\footnotetext{
8 A Epidemiologia tende a significar distintos conceitos dependendo da base científica que a propõe, portanto, coexistem várias correntes do pensamento epidemiológico (BREILH, 1997).

9 Conceituação elaborada a partir de ROUQUAYROL, M. Z. Epidemiologia \& Saúde. Rio de Janeiro: Medsi Editora Médica e Científica Ltda., 1994.
} 
minar "Qualidade de Vida". A maioria destes instrumentais são de fontes anglo-saxãs, alguns devidamente traduzidos e adaptados para a realidade brasileira. Esta perspectiva de compreensão do fenômeno saúde, trata-a a partir de indicadores individuais e coletivos, psicológicos e econômicos, relacionados à prática de atividades físicas e hábitos alimentares, entre outros elementos.

O Conselho Nacional de Saúde organiza conceitualmente saúde a partir da:

$8^{a}$ Conferência Nacional de Saúde [que] concebeu a saúde como "direito de todos e dever do Estado" e ampliou a compreensão da relação saúde/doença como decorrência das condições de vida e trabalho, bem como do acesso igualitário de todos aos serviços de promoção, proteção e recuperação da saúde, colocando como uma das questões fundamentais a integralidade da atenção à saúde e a participação social [...]. (CNS, 1998).

Para o médico social Scliar (2007, p. 30), o conceito de saúde "reflete a conjuntura social, econômica, política e cultural". Desta perspectiva, afirma que "saúde não representa a mesma coisa para todas as pessoas. Dependerá da época, do lugar, da classe social [...] de valores individuais, de concepções científicas, religiosas, filosóficas" ${ }^{10}$.

A Carta Magna do Brasil aprovada em 1988, em seu artigo 196, não discute o conceito de saúde, contudo, registra que a "saúde é direito de todos e dever do Estado, garantido mediante políticas sociais e econômicas que visem à redução do risco de doença e de outros agravos e ao acesso universal e igualitário às ações e serviços para a promoção, proteção e recuperação" (BRASIL, 1988). Este princípio é o mesmo que delineia a política pública a ser desenvolvida no Sistema Único de Saúde (SUS) no país.

\footnotetext{
${ }^{10}$ Ver mais sobre a história do conceito saúde em: SCLIAR, M. História do Conceito de Saúde. PHYSIS: Rev. Saúde Coletiva, Rio de Janeiro, v. 17, v. 1, p. 29-41, 2007.
} 
$\mathrm{Na}$ perspectiva do conceito de saúde unificada, ou One Health ${ }^{11}$, derivado das elaborações de Calvin Schwabe, um médico veterinário, as saúdes humana, animal e ambiental devem ser tratadas como uma continuidade e não de forma isolada e estanques. Segundo essa perspectiva, a abordagem a questões de saúde deve ser preventiva e integrar diversas disciplinas, como ciências da terra, biologia, e ciências sociais.

Kunz (2007) teceu uma crítica acerca da concepção hegemônica no campo da Educação Física sobre a promoção da saúde por via da prática de atividade física. Apontou elementos que não são considerados nesta perspectiva como alimentação, tecnologização do mundo moderno, poluição ambiental, ruído urbano, ausência de sustentação social, baixa estima do sujeito. Indicou a concepção salutogenética ${ }^{12}$ como orientação equilibrada para desenvolver "fatores de proteção à saúde" em que as atividades têm sentido e significado e são amparadas pelo "senso de coerência". Cabe ao Professor de Educação Física focar mais na pessoa que faz o movimento do que no movimento.

Esta é uma contribuição acerca dos parâmetros mais gerais acerca do significado de saúde. A relação direta de causa e efeito, muitas vezes, a tônica nos estudos relativos da Educação Física, entre atividade física e saúde, não é suficiente para explicar as determinações no campo das relações entre Educação Física e Saúde.

Pela amplitude do conceito e a extensão de suas implicações, é necessário atentar-se também para o que as forças produtivas elaboraram enquanto conhecimento e tecnologia possíveis para modificar geneticamente os seres humanos, daí a possibilidade da existência de "fabricar"

\footnotetext{
${ }^{11}$ A origem do termo remonta ao conceito de "medicina única" (One Medicine), cunhado em 1984 pelo veterinário estadunidense Calvin Schwabe. No livro Veterinary Medicine and Human Health, o cientista propôs que "as necessidades críticas do homem incluem a luta contra doenças, a garantia de alimentos suficientes, a qualidade ambiental adequada e uma sociedade em que prevalecem valores humanos". Pesquisas posteriores propuseram incluir a saúde do ecossistema na perspectiva de One Medicine. O conceito foi então expandido, resultando na abordagem One Health, segundo a qual é evidente que as relações entre humanos, animais e meio ambiente estão intimamente ligadas, que há só um mundo, e apenas uma saúde.

12 Salutogênese, conceito elaborado por Aaron Antonovsky (ANTONOVSKY, A. Health, stress and coping: new perspectives on mental and physical well-being. San Francisco: Jossey-Bass, 1979. ANTONOVSKY, A. Unraveling the mystery of health. How people manage stress and stay well. San Francisco: Jossey-Bass, 1987). Ver OLIVEIRA, A.A.B. O tema saúde na Educação Física Escolar: uma visão patogenética ou salutogenetica? In: KUNZ, E.; HILDEBRANDT-STRAMANN, R. (Orgs.) Intercâmbios Científicos em Educação Física e Esportes. Ijuí/RS: Editora Unijuí, 2004. Do latim, salus $=$ saúde, do grego gênese $=$ origem .
} 
superatletas, por exemplo, administrar doping genético e anabolizantes (seja para reposição hormonal ou "bomba"), suplementar a alimentação, medicamentalizar ${ }^{13}$, para além de uma ética biomédica, esportiva e humana.

São elementos que aparecem no bojo dos discursos acerca da saúde. Cabe aos sujeitos que fazem a Educação Física não tomar uma postura anacrônica relativa ao que há de mais avançado na produção tecnológica e ao mesmo tempo viver os contrastes produzidos pela diversificação produzida.

A saúde não é mais uma propriedade do campo de conhecimento da Biomedicina, expande-se para um conjunto de ciências e do campo filosófico que contribui para ampliar a sua compreensão da noção de ausência de doença para os determinantes da realidade concreta em uma perspectiva de totalidade para compreensão do sujeito e as suas relações no/com o mundo, não devendo então ser descolada das questões referentes às compreensões de saúde da materialidade concreta do modo de produção da vida.

A saúde é um elemento constituidor do/no processo de organização, manutenção e reprodução da vida como uma totalidade, síntese de múltiplas determinações em que as diferentes dimensões da vida estão imbricadas no modo de produção da sociedade. Indicativos pelos quais se constitui o campo das Ciências Sociais em Saúde. Antonowsky (1987 apud TAFFAREL, 2010, p. 174 e 175) destaca que:

[...] é imprescindível o conhecimento e o pensamento sobre saúde. Não se desenvolve o sentido da vida, o senso de coerência, a autoestima e a assistência social sem conhecimento, sem pensamento crítico. Desenvolver o "senso de coerência" para a vida exige, portanto, o pensamento crítico, a atitude crítica, e isso não brota espontaneamente, pois exige qualidade nas relações humanas, condições de vida dignas e aprendizagens que a escola pode contribuir (ANTONOWSKY, 1987 apud TAFFAREl, 2010, p. 174-175).

Em um sentido de síntese, Pinto (2012, p. 18) desenvolve uma compreensão acerca de saúde com a qual temos acordo, porque aponta elementos de crítica sócio histórica em uma perspectiva materialista dialética:

Compreendemos a saúde como um processo que é a síntese de múltiplas determinações, e que as dimensões biológicas e ambien-

13 Trata do uso de medicamentos de forma abusiva. 
tais da vida humana estão subsumidas às características do modo de produção da vida em cada sociedade em seu desenvolvimento histórico.

Nesta perspectiva, apontamos para a necessidade de compreensão da unidade dialética entre leis biofísicas e naturais e leis sócio históricas como estruturantes da concepção de saúde, sem isolar o fenômeno dos seus determinantes históricos.

Contudo, se faz necessário alertar que no processo de constituição do campo da saúde enquanto espaço-tempo das práticas sociais no/do cuidado com o corpo/pessoa, há o predomínio hierarquicamente estabelecido do saber-atuação médico enquanto profissional da saúde. Assim, quando se trata da área de conhecimento e intervenção da Educação Física na perspectiva do campo da saúde, mesmo no século XXI, sobrepuja-se o pensamento médico numa constatada prática de subserviência, a que também todos os outros profissionais da saúde desenvolvem, por força dos dispositivos legais, mas principalmente, pela ampla aceitação do discurso médico/medicalizante ${ }^{14}$ que conquistou o seu estatuto de autoridade em uma sociedade medicalizada.

Aprendemos com Marx (1990) em seu denso relato n'O Capital que as condições impostas à Classe Trabalhadora, desde a sua gênese, têm sido impingidas pelo Sistema Capitalista de forma a desumanizar o trabalhador e de certa forma acentuada, a trabalhadora, para que ele e ela não se reconheçam enquanto Seres Humanos, que percam completamente a dignidade de viver e que se conformem à situação de sobrevida, naturalizando esta condição desumanizada. O escrito de Marx datado de meados do terceiro quarto do século XIX (aproximadamente 1867) continua uma descrição farta de fidelidade da realidade vigente, ressalvados alguns avanços tecnológicos, de logística e outros, contudo, o cerne do trabalho segue atual, lamentavelmente. Concordamos com Arrizabalo Montoro (2014), que neste cenário e conjuntura atual, as forças produtivas, categoria social, no estágio imperialista do capitalismo, sofrem destruição para manter os níveis do rentismo.

A "mecânica" do Sistema Capitalista para gerar o mais-valor se refina, transformando a força de trabalho em mercadoria, e como tal, cria a ilusão no trabalhador e na trabalhadora de que ele e ela podem ter autonomia quanto à sua vida/força de trabalho mesmo que as condições a que estejam submetidos denotem o quanto esta assertiva não seja real.

${ }^{14}$ Medicalizar é um processo artificial que transforma questões políticas e sociais em individuais, biológicas, orgânicas. Sua face mais perversa é a patologização. 
Nesta relação trabalho-condições de trabalho-trabalhador/trabalhadora, no decorrer da história, o próprio trabalhador e trabalhadora foi/é responsabilizado pelas próprias condições de saúde ou de não-saúde, imputando-lhe culpa, ainda que objetivamente, estas condições fossem criadas, alimentadas e retroalimentadas pela sistemática da produção e extração da força de trabalho e geração do mais-valor.

\section{A teoria do conhecimento e educacional e as contradi- ções da escola}

Para tratar mais especificamente no âmbito da Educação a partir da compreensão de que a Saúde é um dos fatores ideológicos utilizado no processo educacional e de formação profissional, é necessário à Educação Física conhecer e se apropriar, para garantir a integralidade da formação.

O desenvolvimento do tema da saúde, em particular ao nível de seu conceito, demanda-nos defini-lo a partir de uma dada teoria do conhecimento, a partir da qual se estabelecem as concepções de realidade (e/ou sociedade), de ser humano e de conhecimento.

Em um registro materialista histórico-dialético, o ser humano é um "ser de natureza social", isto é, "[...] tudo o que tem de humano nele provém da sua vida em sociedade, no seio da cultura criada pela humanidade" (LEONTIEV, 1978, p. 261, grifo do autor). Em outras palavras, o ser humano não nasce humano, torna-se humano a partir da atividade prática de transformação material da natureza. Na medida em que os meios necessários à sua sobrevivência não são garantidos de forma imediata pela natureza, os seres humanos desenvolvem uma forma de intercâmbio com ela na perspectiva da produção, ativa e intencional, dos meios de sua subsistência (o trabalho). Em suma: "Portanto, o que não é garantido pela natureza tem que ser produzido historicamente pelos homens, e aí se incluem os próprios homens. Podemos, pois, dizer que a natureza humana não é dada ao homem, mas é por ele produzida sobre a base da natureza biofísica" (SAVIANI, 2012, p. 13). No quadro da concepção de ser humano como ser social, supera-se a separação entre leis biológicas e leis sócio históricas (e a pretensa hegemonização das primeiras) para a explicação do que é a realidade e a sociedade e, por extensão, o que é saúde ${ }^{15}$.

15 Conforme Leontiev (1978, p. 264): “O homem não está evidentemente subtraído ao campo de acção das leis biológicas. O que é verdade é que as modificações biológicas hereditárias não determinam o desenvolvimento sócio-histórico do homem e da humanidade; este é doravante movido por outras forças que não as leis da variação e da here- 
No processo de transformação da natureza, os seres humanos produzem um "mundo humano" ou o "mundo da cultura", que necessita ser transmitido e apropriado de geração em geração como condição (e simultaneamente, consequência) ao desenvolvimento histórico da humanidade (SAVIANI, 2012).

Tão importante quanto este aspecto, é o fato de que, no processo de produção da sua existência, os seres humanos desenvolvem relações entre si independentes de sua vontade. Estas relações correspondem a um determinado estágio de desenvolvimento das forças produtivas empregadas neste processo (MARX, 2008). A unidade dialética entre forças produtivas e relações de produção constitui a base material ou a estrutura econômica da sociedade - base sobre a qual "se eleva uma estrutura jurídica e política e à qual correspondem formas sociais determinadas de consciência" (MARX, 2008, p. 47). Portanto, de acordo com Marx (2008, p. 47): “O modo de produção da vida material condiciona o processo de vida social, política e intelectual. Não é a consciência dos homens que determina o seu ser; ao contrário, é o seu ser social que determina sua consciência.". Sobre esta questão, remetemo-nos, ainda, para a "Ideologia Alemã", em que Marx e Engels demarcam que:

Os homens são os produtores de suas representações, de suas idéias e assim por diante, mas os homens reais ativos, tal como são condicionados por um determinado desenvolvimento de suas forças produtivas e pelo intercâmbio que a ele corresponde, até chegar às suas formações mais desenvolvidas. [...] não se parte daquilo que os homens dizem, imaginam ou representam, tampouco homens pensados, imaginados ou representados para, a partir daí, chegar aos homens de carne e osso; parte-se dos homens realmente ativos e, a partir de seu processo de vida real, expõe-se também o desenvolvimento dos reflexos ideológicos e dos ecos desse processo desse processo de vida (MARX; ENGELS, 2007, p. 94).

Portanto, no decurso da produção da existência, como condição e consequência do modo de produzir a vida, os seres humanos desenvolvem formas de representação do real no pensamento. As diversas formas de conhecer/conhecimento desenvolvidas historicamente encontram-se organicamente conectadas com os modos de produção das existências, aos quais correspondem diferentes graus de desenvolvimento das forças produtivas e das relações de produção. O conhecimento exerce um papel de mediação,

ditariedade biológicas.". 
no processo de produção e reprodução da vida, entre a realidade material e a ação humana de transformação desta realidade (MORSCHBACHER, 2016).

Em uma analogia à Marx e Engels em "A Ideologia Alemã", nos processos de produzir conhecimentos não se trata de descer do "céu à terra", mas de se elevar "da terra ao céu" (MARX; ENGELS, 2007, p. 94) - isto é, de apreender, no pensamento, as conexões (e determinações) entre o processo de produzir e reproduzir a existência e os fenômenos a serem conhecidos, sob pena de permanecer ao nível daquilo que imediatamente se manifesta (a aparência em detrimento da essência - o mundo da "pseudoconcreticidade" (KOSIK, 1976)).

A ciência, que apresenta uma estrutura interna que a distingue das demais formas de conhecimento, consiste no principal instrumento para a penetração racional gradativamente mais profunda (e mais rica de determinações) no real (MORSCHBACHER, 2016). Busca-se, mediante a ciência, em um registro materialista, histórico e dialético, apreender as leis e categorias que regem a gênese, o desenvolvimento, a forma e conteúdo atuais dos fenômenos (e suas tendências de crise e desaparecimento) - portanto, o seu movimento. Trata-se, portanto, de apreender os fenômenos nas suas múltiplas determinações e no seu movimento real. Conforme Marx (1990, p. 21, grifo do autor):

A investigação tem de se apropriar do material em pormenor, de analisar as suas diversas formas de desenvolvimento e de seguir a pista do seu vínculo interno. Somente depois de completado este trabalho pode o movimento real ser exposto em conformidade. Se se consegue isso e se a vida do material se reflecte, então, idealmente [ideell], poderá parecer que se está perante uma construção a priori.

Na medida em que a ciência é a expressão mais desenvolvida da capacidade humana de conhecer a realidade e de expressá-la na forma de conceitos, esta tem um papel fundamental como conteúdo do processo de humanização que se opera pelo trabalho educativo - que corresponde, conforme Saviani (2012, p. 13), ao "ato de produzir, direta e intencionalmente, em cada indivíduo singular, a humanidade que e produzida histórica e coletivamente pelo conjunto dos homens". A capacidade de transformação da realidade pela ação humana (nos sentidos imediato, mediato e histórico seja no quadro imediato da manutenção da existência, seja no do revolucionamento do modo de produção capitalista) encontra-se intimamente co- 
nectado à apropriação do conhecimento (científico) pelos trabalhadores e trabalhadoras.

\section{À guisa de conclusão - a defesa da Educação Física e do conhecimento da cultura corporal em sua forma mais desenvolvida na educação infantil}

Dado que a história de toda a sociedade é a história da luta de classes (MARX; ENGELS, 1982), o conhecimento é também apropriado de forma privada pela classe dominante (capitalista) e socializado à classe trabalhadora dentro dos limites necessários à manutenção da reprodução do capital. Ademais, a própria objetividade do conhecimento ${ }^{16}$ é sistematicamente relativizada pela classe capitalista - classe que, beneficiária das condições de exploração, em um modo de produção crescentemente contraditório, busca opor-se à objetividade do conhecimento a fim de obstaculizar o desvendamento dos mecanismos destas condições. À classe trabalhadora, não só interessa a objetividade do conhecimento, como lhe é vital o acesso ao conhecimento objetivo e expresso nas suas formas mais elaboradas (SAVIANI, 2012).

Neste sentido Teixeira (2018), tendo como objeto de estudo a Educação Física na Pré-escola, respondeu com uma investigação que culminou em sua tese de doutorado, à pergunta-síntese sobre quais orientações específicas devem nortear o ensino da Educação Física escolar na Pré-escola a partir das contribuições da abordagem Crítico-Superadora?

Seu estudo apresentou parâmetros teórico-metodológicos de uma Educação Física Crítico-Superadora para o primeiro ciclo de escolarização, especificamente para a Pré-escola, e contribuiu para superar a negação do conhecimento referente às atividades da Cultura Corporal na rede pública de ensino. Teixeira (2018) sustenta a tese de que o trato com o conhecimento científico do campo da Cultura Corporal deve-se iniciar na pré-escola.

Ao confrontar concepções científicas sobre o objeto de estudo da Educação Física, a saber, a Cultura Corporal e o movimento, Teixeira

\footnotetext{
${ }^{16}$ Compreendemos a objetividade do conhecimento como uma questão gnosiológica, que diz respeito, conforme Saviani (2012), "à correspondência ou não do conhecimento com a realidade à qual se refere.”. A objetividade do conhecimento liga-se, portanto, com a possibilidade da verdade objetiva, definida por Lénine (1982, p. 79, grifos do autor): “a 'verdade objectiva' (gegenständliche Wabrheit) do pensamento não significa outra coisa senão a existência dos objectos (= 'coisas em si') reflectidos verdadeiramente pelo pensamento").
} 
(2018) critica as orientações oficiais que influenciam as políticas curriculares, e destaca a relevância do domínio dos conhecimentos historicamente produzidos e acumulados sobre a cultura corporal (incluindo a dimensão da técnica) para a humanização.

De forma inédita, apresenta uma proposta de organização do trato pedagógico do conhecimento da Ginástica na Pré-escola, a partir da reorganização do primeiro ciclo de escolarização apresentada pelo Coletivo de Autores em 1992. O faz levando em consideração, também, as contribuições recentes de Martins, Abrantes, Facci (2016), sobre a periodização histórico-cultural do desenvolvimento psíquico, e dos conhecimentos da motricidade infantil.

É na infância, na mais tenra idade, que os seres humanos se aproximam das elaborações produzidas pela humanidade. Não é diferente em relação às concepções de saúde e seus fundamentos.

Concluímos, destacando, que o ensino sistematizado dos conteúdos da Cultura Corporal devem fazer parte do núcleo central do currículo da Educação Infantil - desde as creches - primeira etapa do processo da educação escolarizada, uma vez que o ser social, principalmente nesta fase da vida, acessa a humanidade - pelo domínio dos signos culturalmente desenvolvidos por meio da sua organização corporal, condição que contribui para o desenvolvimento infantil nas suas múltiplas dimensões, e que o ensino orientado pela abordagem Crítico-Superadora das atividades da Cultura Corporal potencializa o desenvolvimento do psiquismo infantil.

Enfrentamos, assim, a contradição da negação do conhecimento na escola que é favorável as classes dominantes e que consiste, segundo Saviani e Duarte (2012, desde as políticas educacionais, passando pelas teorias pedagógicas que postulam para a escola todas as funções menos a de transmissão sistemática de conhecimento no trabalho em sala de aula.

Considerando que as contradições não são estanques, mas movimentam o real concreto segundo interesses de classes, nos posicionamos de acordo com os interesses da classe trabalhadora, "pela efetivação da especificidade da escola, fazendo do trabalho de socialização do conhecimento o eixo central de tudo o que se realiza no interior dessa instituição, ou seja, aquilo que dá sentido à sua existência" (SAVIANI; DUARTE, 2012, p. 3-4).

Em tempos de obscurantismo, de fundamentalismo, de negação da ciência e da função social da escola, reafirmar a compreensão mais avançada sobre saúde e sua relação com a Educação Física no currículo escolar, é de grande relevância social. Nos colocamos assim, ombro-a- 
ombro com aqueles intelectuais orgânicos da classe trabalhadora que compreendem o momento histórico de transição para outro modo de vida, o modo de vida. A crise sanitária provocada pela pandemia do Coronavírus, que provoca a COVID-19 intensificou as determinações históricas que nos permitem concluir este texto com esperança de que não prevalecerá a barbárie, mas, sim, o projeto histórico socialista.

\section{Referências}

ALMEIDA, Silvio. Racismo estrutural. São Paulo: Sueli Carneiro, 2019.

ALMEIDA FILHO, Naomar de. A problemática teórica da determinação social da saúde (nota breve sobre desigualdades em saúde como objeto de conhecimento). Saúde em Debate, Rio de Janeiro, v. 33, n. 83, p. 349-370, set./dez. 2009.

\section{ARRIZABALO MONTORO, Xabier. Capitalismo y Economía Mundial:} bases teóricas y análisis empírico para la comprensión de los problemas económicos del siglo XXI. Madrid: Instituto Marxista de Economía, 2014.

BAGRICHEVSKY, Marcos; PALMA, A. Questionamentos e incertezas acerca do estatuto científico da Saúde: um debate necessário na Educação Física. Revista da Educação Física da UEM, Maringá, v. 15, n. 2, p. 57-66, 2004.

BRASIL. Constituição da República Federativa do Brasil. 1988. Disponível em: < http://www.planalto.gov.br/ccivil 03/constituicao/constituicao.htm>. Acesso em: 03 jul. 2020.

CNS - CONSELHO NACIONAL DE SAÚDE. MINISTÉRIO DA SAÚDE. BRASIL. Resolução $\mathbf{n}^{\circ}$ 287, de 08 de outubro de 1998. Disponível em:

$<$ http:bvsms.saude.gov.br/bvs/saudelegis/cns/1998/

res0287 $08 \quad 10 \quad$ 1998.html>. Acesso em: 03 jul. 2020.

DEVIDE, Fabiano Pries. Educação Física, Qualidade de Vida e Saúde: campos de intersecção e reflexões sobre a intervenção. Movimento: Porto Alegre, v. 8, n. 2, p.77-84, maio/agosto, 2002.

FRIGOTTO, Gaudêncio. Trabalho como princípio educativo. In.: CALDART, Roseli; PEREIRA, Isabel Brasil; ALENTEJANO, Paulo; FRIGOTTO, Gaudêncio (Org.). Dicionário da Educação do Campo. Rio de Janeiro, São Paulo: Escola Politécnica de Saúde Joaquim Venâncio, Expressão Popular, 2012.

KOSIK, Karel. Dialética do concreto. Tradução Célia Neves e Alderico Toríbio. 3. ed. Rio de Janeiro: Paz e Terra, 1976. 
KUNZ, Elenor. Ministério da Saúde adverte: viver é prejudicial à saúde. In.: BAGRICHEVSKY, M.; PALMA, A.; ESTEVÃO, A. (Org.) A saúde em debate na Educação Física. Volume 3. Ilhéus: Editus, 2007.

HACK, Cássia. Formação de Professores e Professoras de Educação Física no Brasil e o embate de projetos no campo de conhecimento da Saúde: contribuições da Teoria Pedagógica Histórico-Crítica. 235 f. 2017. Tese (Doutorado em Educação) - Faculdade de Educação, Universidade Federal da Bahia, Salvador, 2017.

LÉNINE, Vladmir Ilitch. Materialismo e empiriocriticismo. Lisboa: Avante, 1982.

LEONTIEV, Alexei Nikolaevich. O desenvolvimento do psiquismo. Lisboa: Livros Horizonte, 1978.

MALANCHEN, Julia. Cultura, conhecimento e currículo: Contribuições da pedagogia histórico-crítica. Campinas: Autores Associados, 2016.

MARTINS, Lígia Márcia; ABRANTES, Angelo Antônio; DIAS, Marilda Gonçalves. Periodização histórico cultural do desenvolvimento psíquico: do nascimento a velhice. Campinas: Autores Associados, 2016.

MARX, Karl. Contribuição à crítica da Economia Política. Tradução Florestan Fernandes. 2. ed. São Paulo: Expressão Popular, 2008.

O Capital: crítica da Economia Política. 1 v. Livro 1. Tradução José Barata-Moura, João Pedro Gomes, Pedro de Freitas Leal, Manuel Loureiro e Ana Portela. Lisboa: Edições Avante, 1990.

MARX, Karl; ENGELS, Friedrich. A ideologia alemã: crítica da mais recente filosofia alemã em seus representantes Feuerbach, B. Bauer, e Stirner, e do socialismo alemão em seus diferentes profetas. Tradução Rubens Enderle, Nélio Schneider, Luciano Cavini Martorano. São Paulo: Boitempo, 2007. ; _ Manifesto do Partido Comunista. In.: MARX, Karl;

ENGELS, Friedrich. Obras Escolhidas em Três Tomos. Tradução de José Barata-Moura, Eduardo Chitas, Álvaro Pina, Fernando Silvestre. Lisboa: Edições Avante, 1982. p. 106-136. t. 1.

MORSCHBACHER, Márcia. Formação de professores: proposições para a formação para o trabalho científico na Licenciatura em Educação Física. 363 f. 2016. Tese (Doutorado em Educação) - Faculdade de Educação, Universidade Federal da Bahia, Salvador, 2016.

PINTO, Ana Lucia Sousa. O tratamento dispensado à categoria saúde no currículo de graduação em educação física. 2012. 157 f. Dissertação (Mestrado em Educação). Universidade Federal da Bahia, 2012. 
RAMOS, Marise. Concepções e práticas pedagógicas nas escolas técnicas do Sistema Único de Saúde: fundamentos e contradições. Trab. educ. saúde, Rio de Janeiro, v. 7, supl. 1, p. 153-173, 2009.

SAVIANI, Dermeval; DUARTE, Newton. Pedagogia histórico-critica e luta de classes na Educação Escolar. Campinas: Autores Associados, 2012.

Pedagogia Histórico-Crítica: Primeiras Aproximações. 11. ed. rev. $1^{a}$ reimpr. Campinas: Autores Associados, 2012.

SCLIAR, Moacyr. História do Conceito de Saúde. PHYSIS: Rev. Saúde Coletiva, Rio de Janeiro, v. 17, n. 1, p. 29-41, 2007.

SOARES, Carmem Lucia. Educação Física: Raízes Europeia e Brasil. 5. ed. São Paulo: Autores Associados, 2017.

STIGGER, Marco Paulo. (Org.) Educação Física + Humanas. Campinas: Autores Associados, 2015.

TEIXEIRA, David Romão. Educação Física na pré-escola: contribuições da abordagem crítico superadora. 156 f. 2018. Tese (Doutorado em Educação) Faculdade de Educação, Universidade Federal da Bahia, Salvador, 2018.

TAFFAREL, Celi Nelza Zülke. Sobre o Sistema de Complexo HomemEsporte-Saúde: reflexões a partir de contribuições da Alemanha. In.: MATIELLO JR, Edgar; CAPELA, Paulo; BREILH, Jaime (Org.). Ensaios Alternativos Latino-Americanos de Educação Física, Esporte e Lazer. Florianópolis: Copiart, 2010. 
